\title{
Perceived Satisfaction of Emergency Remote Teaching: More Evidence from Thailand
}

\author{
Kevin Fuchs \\ Prince of Songkla University, Phuket, Thailand \\ https://orcid.org/0000-0003-3253-5133
}

\begin{abstract}
The sudden shift from physical classroom education towards emergency remote teaching (ERT) in higher education during the unprecedented global pandemic caused an abrupt change in the learning environment for students and educators alike. The disruptive overnight change and conversion of entire courses to emergency remote teaching caused concern for not only educators, but also students that had little time to adapt to the new circumstances. While the embedment of technologies in the classroom is not a new concept, this quantitative research expands a case study that sought to examine the perceived satisfaction of undergraduate students with the emerging paradigm of ERT. Responses based on empirical data $(n=450)$ as well as secondary data $(n=219)$ were analyzed to conclude that, in particular, younger freshmen students struggled more with online emergency remote teaching than their older peers. Furthermore, the study identified numerous similarities between both data samples. The current research informs educators about student perceptions and preferences during these extraordinary circumstances of uncertain duration. Furthermore, the paper concludes with recommendations that aim to provide institutions and educators with practical guidance on how to tackle the outlined issues.
\end{abstract}

Keywords: Emergency remote teaching; Technology-enhanced learning; Thailand; Online learning; Higher education

\section{Introduction}

The universality of information technology has been influencing almost all aspects of our lives: the way we work, interact with others, process data into information, analyze and share information, entertain ourselves, and enjoy tourism (Palvia et al., 2018). Due to the threat of COVID-19, universities are facing decisions about how to continue teaching and learning while keeping their faculty, staff, and students safe from a public health emergency that is moving fast and is not well understood. Many institutions have opted to cancel all face-to-face classes, including lab-based classes and seminars. They have mandated that faculties move their courses online to help prevent the spread of 
the virus that causes COVID-19 (Fuchs, 2021a). This unprecedented situation created an entirely new phenomenon: due to the severe nature of the virus, entire curricula were moved to online education overnight. The challenge herein was not limited to the educators, who found themselves in a situation of needing to teach their entire syllabus online, but also extended to the students, who needed to adapt to a new learning environment instantaneously (Whalen, 2020).

As a response to the global education crisis, online emergency remote teaching has been put into practice. It is a complex process that requires careful planning, designing, and determination of aims in order to create an effective learning ecology (Themelis \& Sime, 2020). The temptation to compare online learning to face-to-face instruction in these circumstances will be great. Online learning carries a stigma of being lower in quality than face-to-face learning, despite research showing otherwise. These hurried moves online by so many institutions at once could seal the perception of online learning as a weak option when, in truth, nobody making the transition to online teaching under these circumstances will truly be designed to take full advantage of the affordances and possibilities of the online format (Hodges et al., 2020).

This paper is an expansion of an earlier study done by Fuchs and Karrila (2021) that sought to examine the perceived satisfaction of students in higher education concerning emergency remote teaching amid COVID-19 in Thailand. Fuchs and Karrila (2021) identified that most undergraduate students prefer a traditional on-site classroom arrangement, but were satisfied with the alternative ERT that was delivered fully online. The study highlighted that the students perceived knowledge, friendliness, and patience as the most important characteristics of their lecturer in these circumstances. However, the limited sample size from the previous study $(n=219)$ would not suffice to generalize the results to a larger population, nor allow for validation in different geographical parts of Thailand. This paper therefore aims to expand on the original research setting and to meet the following research objectives:

1) To seek validation of previous research results through an increased sample size

2) To identify whether the perceived satisfaction from undergraduate students varies in a different geographical setting

3) To recognize a similarity or dissimilarity between specific factors based on geographical location, i.e. in Northeastern vs. Southern Thailand

Moreover, the research was guided by the following research question: "How do undergraduate students in Northeastern Thailand perceive satisfaction with the emerging paradigm of emergency remote teaching during COVID-19?"

\section{Literature Review}

\subsection{Online learning in higher education}

The COVID-19 has resulted in schools shut all across the world. As a result, education has changed dramatically, with the distinctive rise of e-learning, whereby teaching is undertaken remotely and on digital platforms. As shown in a previous study, effective time management was the second-highest-rated 
advantage of online education, with students having more freedom to control their time and not being constrained by predetermined schedules (Martin et al., 2020). Another study found that, depending on the teaching methods used, the ability to use multiple virtual classrooms at the same time could improve student interest and involvement, allowing for smaller group discussions during online lectures (Fuchs, 2021b). Furthermore, a combination of time and location versatility was claimed as one of the key advantages of online education. The benefit of place and time flexibility works both ways, allowing students and educators to choose the best work environment for them.

Additionally, time saved by eliminating a daily commute can be spent in more study time, increasing the likelihood of success. The variety of digital resources that can be incorporated into the virtual classroom was mentioned as another advantage of online education. According to Downes (2019) in his Connectivism-based educational theory, the online medium provided an opportunity and experience to connect with students from various disciplines, backgrounds, and cultures (Downes, 2019). Since the early 2000s, the paradigm of online education has changed radically. Most notably, the Internet is connecting an ever-increasing number of people all over the world. According to the United Nations nearly 4.68 billion people will have access to the Internet in the year 2020. This figure reflects roughly 58 percent of the world's population, so it is no wonder that online education is growing in tandem.

\subsection{Challenges and opportunities related to online education}

Earlier research by Fuchs and Karrila (2021), Sun and Chen (2016), Kyne and Thompson (2020), Delnoij et al. (2020), and Fuchs (2021c) claim that online education has numerous advantages, including the ability to study remotely without having to engage in a daily rush hour in metropolitan areas. Furthermore, another advantage listed was timely and frequent feedback from the course instructor through digital evaluations and electronic communication (Kyne \& Thompson, 2020). Other advantages of online education include the multi-media experience in a well-designed virtual classroom with various technical elements (Fuchs, 2021c). Moreover, of course, there were monetary benefits resulting from reduced costs and, therefore, lower tuition fees for participating students (Sun \& Chen, 2016).

Online education and technology-enhanced education are certainly not new concepts; they have been around for quite some time. However, rising curiosity has ignited a big trend in these fields (Sun \& Chen, 2016; Kyne \& Thompson, 2020). Educators were searching for a way to do some of their teachings online, or at the very least incorporate technology into their classrooms (Fuchs, 2021b; Fuchs, 2021c). The pedagogy of active learning, in particular, has intensified the movement toward technology-enhanced education, which has the benefits of increased student participation, improved learning outcomes, and, as a result, higher retention rates (Delnoij et al., 2020). However, many of the outlined benefits are not transferable to the paradigm of emergency remote teaching in a crisis, wherein this emerging paradigm carries its own set of distinguishing characteristics. 


\subsection{The emerging paradigm of ERT}

As a result of crises, emergency remote teaching (ERT) is a temporary transition in instructional delivery to an alternative delivery model, wherein it is implied that teaching is carried out entirely online. It was also stated that online education has been studied for decades, with a consensus on the elements that do not contribute proportionally to the efficacy of online education. These characteristics include but were not limited to modality, pacing, studentinstructor ratio, pedagogy, the role of assessment, the instructor's role, the student's role, communication channels, and sources of feedback. These characteristics will invariably be evident in an effective ERT class. The lack of time available for educators to change their instructional materials - in the event of a last-minute switch from classroom to online - may potentially indicate an unsuitable learning atmosphere for students.

Kyne and Thompson (2020) conducted a case study that described many challenges faced by students during their fully online semester. Completing labbased tasks, navigating Moodle (LMS), and engaging with online content were among them. If the course content is not carefully and intentionally designed, "undergraduate students claim a lack of socialization with peers and low engagement with the course materials" as primary reasons for their dissatisfaction, according to a similar study (Fuchs, 2021a). Furthermore, Wilcox and Vignal (2020) discovered that the two most common difficulties students faced as a result of ERT were (1) course inception and (2) learning environment. The most frequently mentioned issue in the above group was unreliable Internet access that hindered the students' learning experience.

Participants said the learning process was uncomfortable and unpleasant, according to Gelles et al. (2020). Although there are many benefits and opportunities in the online education paradigm, it should be recognized that it is not without its difficulties and flaws. Certainly, lack of student engagement (Fuchs, 2021c), willingness to meet learning results (Zlatkin-Troitschanskaia et al., 2016), and involvement of low-performing students (Fay \& Zavattaro, 2016) were all difficulties found in previous studies. However, given the existence of the substantial changes that emergency remote teaching could entail, there is the potential for a new set of challenges to arise.

\subsection{Defining students satisfaction}

Satisfaction is a euphoric feeling that occurs when a person's needs and desires have been met (Suikkanen, 2011). It is a state of mind of a person that has achieved or perceived a result that has exceeded their expectations (Busacca \& Padula, 2015). As a result, satisfaction can be described as an experience of receiving expected results. In related research, satisfaction is often portrayed as the positive difference between the perceived importance and the perceived performance of an attribute or action (Muhsin et al., 2020). In other words, satisfaction refers to the satisfaction or dissatisfaction experienced as a result of contrasting perceived results to expectations (Suikkanen, 2011; Padula, 2015).

Generally, students are satisfied when the perceived performance of a specific service or action outranks the perceived expectation of the same service/action. 
When a person perceives that service encountered as good, they will be satisfied. When the perceived performance of the service or action is below the perceived expectation, then that person would be dissatisfied with the result: Satisfaction $(S)=$ Perceived Importance (I) - Perceived Performance (P).

The measurement of a student's educational experiences leads to a short-term disposition of satisfaction. It is the product and effect of an educational system and is a positive indicator of student loyalty (Weerasinghe \& Fernando, 2017; Muhsin et al., 2020). In conclusion, student satisfaction can be understood as a function of the relative level of experiences and perceived performance concerning educational services during the study period (Suikkanen, 2011; Padula, 2015; Weerasinghe \& Fernando, 2017).

\section{Methodology}

\subsection{Sample}

The data were collected from undergraduate students of all years who were enrolled in a full-time degree program. The sample included degree programs that relate to Business and Management studies. After screening the collected data, a total of 38 responses were discarded. The discarded responses included 13 from another Faculty (i.e. Faculty of Science). Moreover, 8 responses from international exchange students were excluded. However, responses from international degree students were included in the analysis. Finally, 17 inconclusive/incomplete responses were discarded.

Table 1: Socio-demographic characteristics of the participants

\begin{tabular}{|c|c|c|c|c|}
\hline \multirow{2}{*}{$\begin{array}{l}\text { Characteristics } \\
\text { Gender }\end{array}$} & \multicolumn{2}{|c|}{ University $\mathbf{A}^{\mathbf{1}}$} & \multicolumn{2}{|c|}{ University $\mathrm{B}^{2}$} \\
\hline & & & & \\
\hline Male & 58 & $26 \%$ & 125 & $28 \%$ \\
\hline Female & 159 & $73 \%$ & 325 & $72 \%$ \\
\hline Prefer not to say & 2 & $1 \%$ & - & $0 \%$ \\
\hline Total & 219 & $100 \%$ & 445 & $100 \%$ \\
\hline \multicolumn{5}{|l|}{ Year of study } \\
\hline Year 1 & 50 & $23 \%$ & 79 & $18 \%$ \\
\hline Year 2 & 83 & $38 \%$ & 208 & $46 \%$ \\
\hline Year 3 & 43 & $20 \%$ & 76 & $17 \%$ \\
\hline Year 4 & 32 & $14 \%$ & 68 & $15 \%$ \\
\hline Year 5 or above & 11 & $5 \%$ & 19 & $4 \%$ \\
\hline Total & 219 & $100 \%$ & 445 & $100 \%$ \\
\hline \multicolumn{5}{|l|}{ Age range } \\
\hline 18 years old or below & 6 & $3 \%$ & 7 & $2 \%$ \\
\hline $19-20$ years old & 122 & $56 \%$ & 285 & $63 \%$ \\
\hline $21-22$ years old & 68 & $31 \%$ & 114 & $25 \%$ \\
\hline 23 - 24 years old & 16 & $7 \%$ & 30 & $7 \%$ \\
\hline 25 years old or above & 7 & $3 \%$ & 14 & $3 \%$ \\
\hline Total & 219 & $100 \%$ & 445 & $100 \%$ \\
\hline
\end{tabular}


An overall sample size $(n=669)$ was included as a population sample for the data analysis. The confidence level of accurate sampling was estimated at $95 \%$ $(p<0.05)$ and, based on the total student enrollment and sample size that were included, the margin of error was quantified at $4.40 \%$. Based on eligible responses, the representative demographic profile in Table 1 and 2 summarizes the respondents' gender, year of study, age range (all in Table 1), nationality, and preferred mode of study (in Table 2).

Table 2: Socio-demographic characteristics of the participants

\begin{tabular}{lcccc}
\hline Characteristics & University $\mathbf{A}^{\mathbf{1}}$ & University $\mathbf{B}^{\mathbf{2}}$ \\
\hline Nationality & & & & \\
Thai & 184 & $84 \%$ & 360 & $80 \%$ \\
Foreign & 35 & $16 \%$ & 90 & $20 \%$ \\
\hline Total & 219 & $100 \%$ & 445 & $100 \%$ \\
Preferred study mode & & & & \\
Virtual classroom & 54 & $25 \%$ & 117 & $26 \%$ \\
Traditional classroom & 165 & $75 \%$ & 333 & $74 \%$ \\
\hline Total & 219 & $100 \%$ & 445 & $100 \%$ \\
\hline \multicolumn{4}{l}{ 'Secondary Data obtained from University A in Southern Thailand $(\mathrm{n}=219)$} \\
2Empirical Data obtained from University B in Northeastern Thailand $(\mathrm{n}=450)$ \\
\hline
\end{tabular}

\subsection{Research instrument}

Convenience sampling was used to collect the data through a bilingual (Thai and English) self-administered digital survey (e-survey). The e-survey was split into three sections containing a total of 27 questions and was adapted from an earlier case study (Fuchs \& Karrila, 2021). The students were recruited on-site to voluntarily participate in the data collection. Furthermore, the students were prompted for assistance to further distribute the survey amongst their peers. The first section sought to collect data on the participant's socio-demographic profile.

Table 3: Summary of survey items

\section{No. Item}

1. The teacher begins the class with a review of the previous class

2. The teacher presents the material in an interesting and engaging way

3. The teacher presents the material in an organized and coherent way

4. The teacher is knowledgeable about the content of the course

5. The teacher is friendly and patient with the students

6. The course material is well and professionally prepared

7. The course material is easy to access in the LMS

8. Students are engaged to actively participate in the discussion

9. I am learning something which I consider valuable

10. I am finding the course challenging and stimulating 
The second and third sections contained ten (10) items each, wherein the participants were able to express their views on a 5-point Likert-type scale with pre-coded responses for Not Important At All (1), Not Very Important (2), Somewhat Important (3), Very Important (4), and Extremely Important (5) in the second section. Similarly, the third section had pre-coded Likert-type responses for Not At All Satisfied (1), Not Very Satisfied (2), Somewhat Satisfied (3), Very Satisfied (4), and Extremely Satisfied (5). Otherwise, the items in the second and third sections were similar in terms of comparing the perceived importance and performance for each item (Table 3). The structure and content of the administered e-survey were examined for validity by three university lecturers and tested with ten students for comprehension of the survey. These preliminary examinations yielded minor revisions to enhance the clarity of the survey.

\subsection{Survey administration}

The secondary data were taken from an earlier study conducted by Fuchs and Karrila (2021) and were collected in the first quarter of 2021 at a large higher educational institution in southern Thailand. They were collected amid a countrywide ERT policy as a result of the imminent spread of COVID-19. Hereafter, this sample is referred to as University A $\left(\mathrm{n}^{1}=219\right)$.

The empirical data were collected in the second quarter of 2021 at a large higher educational institution in northeastern Thailand and the survey accepted responses for a duration of 96 hours before it was closed for new responses. It was collected in the aftermath of a countrywide ERT policy that was implemented and effectively replaced traditional face-to-face teaching. Henceforth, the sample is referred to as University B $\left(n^{2}=450\right)$. Both institutions are the largest universities in terms of size (i.e. student enrollment and curricula offered) and recognition in the respective areas. Furthermore, they are characterized as government-run institutions of higher education targeting students from middle-class households.

\subsection{Data analysis}

The survey data were examined using JASP and software to obtain an average value (Mean), standard deviation (SD), minimum value (Min), maximum value (Max), the proportion of the data (i.e., a fraction of cases without missing data), and distribution of data for each item. Independent T-tests were performed to determine if there was a significant difference between the means of University A and University B. The data analysis and findings are discussed and interpreted in later sections of this paper.

\section{Results and Discussion}

The results from the empirical data collection and secondary data sample are presented in two separate sections that allow for chronologic analysis and presentation. The first section presents the demographic profiling that was conducted to identify similarities or dissimilarities between the samples based on gender, age range, year of study, nationality, or preferred mode of study. 
The second section presents the mean values of both samples for each attribute and allows for comparison of the results and analysis of student satisfaction with emergency remote teaching. Moreover, the variance from each attribute between the first and second samples was calculated and independent t-tests were performed from both samples to determine whether there was a statistically significant difference between the means in both samples.

\subsection{Demographic profiling of both sample groups}

The socio-demographic profile, consisting of gender, age range, year of study, and nationality, was included in a rigorous cross-analysis wherein different mean ratings based on gender or year of study were detected. However, the results do not suggest a statistical significance or relevance that would further provide value concerning the perceived satisfaction of students with emergency remote teaching in Thailand. However, one particular criterion yielded a noteworthy result. The enclosed graphic (Fig. 1) shows the preferred mode of study based on 17 totally different socio-demographic filters that were applied.

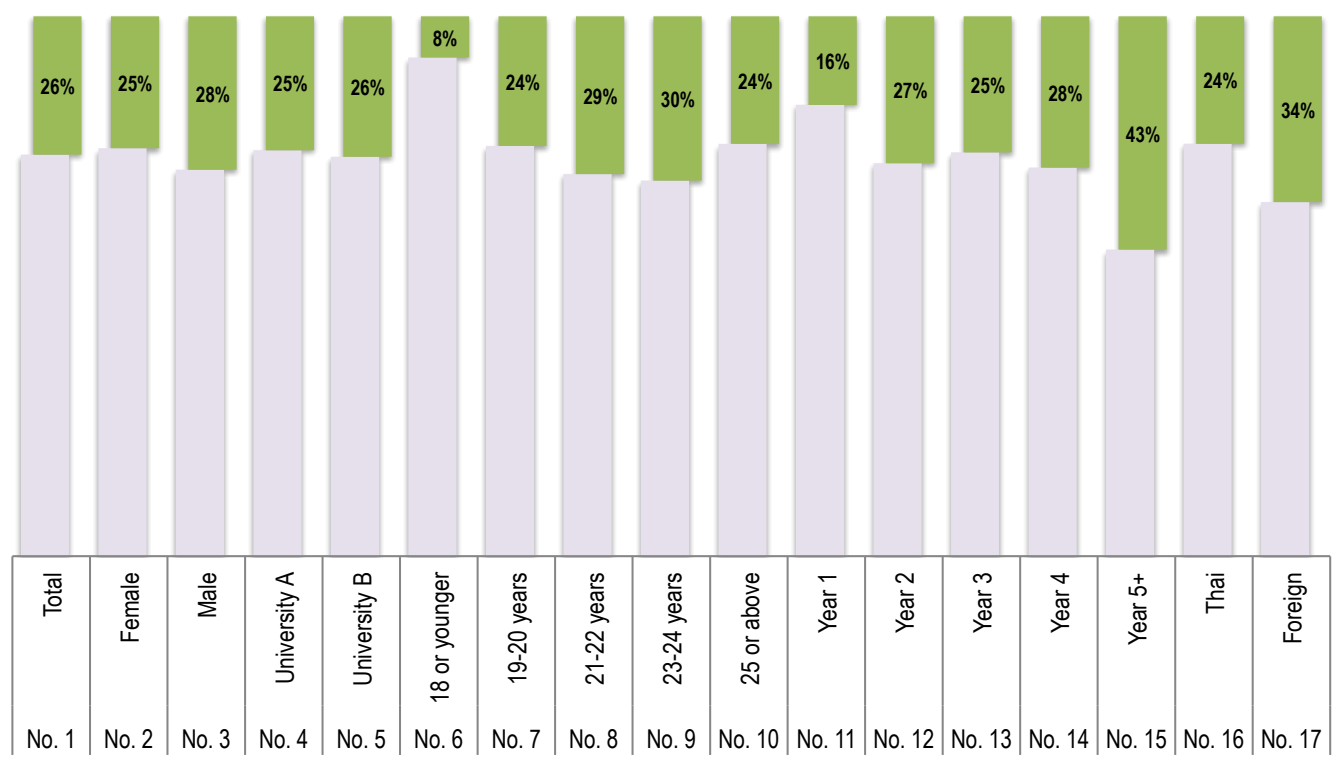

Traditional Classroom Virtual Classroom

Figure 1: Demographic profiling about the students preferred mode of studying

The blue bar signifies the percentage of students that prefer a traditional classroom setting instead of emergency remote teaching, wherein the red bar indicates the percentage of students that prefer emergency remote teaching to a traditional on-site classroom arrangement. To draw a baseline for comparison, 13 of the 17 attributes that were examined yielded a similar proportional response, wherein $74 \%$ of students prefer the traditional classroom and $26 \%$ prefer the virtual classroom during ERT (No. 1). The majority of sociodemographic filters validate this sentiment with a relatively small standard deviation of not more than $2 \%$. However, based on the 17 filters that were applied, four particular settings yielded noteworthy results. Namely, these are: 
No. 6 (18 or younger), No. 11 (Year 1), No. 15 (Year 5+), and No. 17 (Foreign). The first three findings indicate opposing views of the respective groups of participants. The students aged "18 years or younger" expressed their preference toward the traditional classroom environment with $92 \%$, whereas only $8 \%$ of that same group prefer the virtual classroom as part of emergency remote teaching (No. 6). A similar notion is shared amongst the first-year students, wherein $84 \%$ prefer the traditional classroom and $16 \%$ prefer the virtual classroom (No. 11). Generally, the students are aged 17-19 years old in their first year of undergraduate studies. A possible hypothesis therefore derives that freshmen students aged 18 years or younger have a strong preference toward the traditional classroom environment. Another case study suggests that female students in particular struggle with virtual classrooms and claim "lack of socialization, peer interaction and technological challenges" as the main difficulties (Fuchs, 2021a).

Students in their fifth year (and above) expressed an opposing sentiment concerning the preferred mode of study. While $92 \%$ of first-year students prefer the traditional classroom (No. 6), only $57 \%$ of their older peers share that same sentiment (No. 15). A possible explanation for these opposing views could be that freshmen students eagerly wait to commence their study experience upon high school graduation, wherein students in their final years of study are already more independent and have shifted their focus toward work-life-balance rather than study experience, as claimed in a case study by Yamada and Yamada (2018).

Lastly, another notable deviation from the baseline result (No. 1) was the result recorded from foreign degree students (No. 17). 66\% of foreign degree students prefer the traditional classroom, whereas $34 \%$ of them prefer the virtual classroom. While about two-thirds still favor an on-site arrangement, the result deviates by $8 \%$ from the baseline and is even $10 \%$ less compared to their Thai peers (No. 16). Trower and Lehmann (2017) suggest that personal development, immersion into a new culture, and learning a new language are amongst the top reasons for students to study abroad. Thus, a negative deviation from the baseline result suggests a rather contradictory result from these findings and offers room for further research in the future.

\subsection{Importance-performance analysis}

The three highest mean ratings concerning the perceived importance of the attributes (Table 4) at University A are No. 4 (4.37), No. 5 (4.27), and No. 7 (4.13). On the other hand, at University B the following three attributes received the highest mean rating from the participants: No. 5 (4.18), No. 2 (4.17), and No. 4 (4.14). Similar to the results from University A, the participants at University B valued two identical attributes in their top three of most important attributes during ERT. Namely, these are "The teacher is knowledgeable about the content of the course (No. 4)" as well as "The teacher is friendly and patient about the content of the course (No.5)". Both attributes directly address the virtues of the lecturer, as students perceive being knowledgeable, friendly, and patient as the most important characteristics at both institutions. Respectively, the weighted mean ratings from both institutions rank almost identically with No. 4 (4.22) and 
No. 5 (4.21) as the most important attributes during emergency remote teaching. Contrary to the most important attributes, the participants at University A rated item No. 1 (3.73) and No. 10 (3.58) as the least important attributes.

Table 4: Comparison of importance ratings

\begin{tabular}{ccccccc}
\hline \multirow{2}{*}{ No. $^{1}$} & \multicolumn{2}{c}{ University A } & \multicolumn{2}{c}{ University B } & \multicolumn{2}{c}{ Total } \\
& Mean & SD & Mean & SD & Mean & SD \\
\hline 1 & 3.73 & 0.99 & 4.02 & 1.02 & 3.93 & 1.02 \\
2 & 4.03 & 1.01 & 4.17 & 0.98 & 4.12 & 0.99 \\
3 & 4.05 & 0.92 & 4.05 & 0.98 & 4.05 & 0.96 \\
4 & 4.37 & 0.89 & 4.14 & 0.99 & 4.22 & 0.97 \\
5 & 4.27 & 0.96 & 4.18 & 1.02 & 4.21 & 1.00 \\
6 & 4.12 & 0.99 & 4.11 & 1.01 & 4.11 & 1.00 \\
7 & 4.13 & 1.03 & 4.11 & 1.01 & 4.12 & 1.02 \\
8 & 3.98 & 0.95 & 3.91 & 1.08 & 3.93 & 1.04 \\
9 & 3.95 & 0.98 & 4.07 & 1.02 & 4.03 & 1.01 \\
10 & 3.58 & 1.24 & 4.00 & 1.06 & 3.87 & 1.14 \\
\hline
\end{tabular}

${ }_{1}^{1}$ Ratings obtained from a Likert-type five points scale ranging from lowest rating to highest rating, i.e. Not Important At All (1), Not Very Important (2), Somewhat Important (3), Very Important (4), and Extremely Important (5).

Although these two attributes also rank in the bottom three for participants from University B, the lowest mean rating was given to No. 8 (3.91), which asked the participants about the importance of the statement "students are engaged to actively participate in the discussion". Evaluating the totality of both samples, it can be concluded that the lowest to highest mean rating ranges from 3.87 (No 10.) to 4.22 (No. 4), which indicates relatively high importance for all ten attributes. Furthermore, the findings from the first sample taken at University A were affirmed with the second sample from University B, with the virtues of the lecturer perceived by the students as the most important characteristics.

Table 5: Comparison of performance ratings

\begin{tabular}{ccccccc}
\hline \multirow{2}{*}{ No. $^{1}$} & \multicolumn{3}{c}{ University A } & \multicolumn{2}{c}{ University B } & \multicolumn{2}{c}{ Total } \\
& Mean & SD & Mean & SD & Mean & SD \\
\hline 1 & 3.52 & 0.99 & 3.92 & 1.05 & 3.79 & 1.05 \\
2 & 3.62 & 1.04 & 3.80 & 1.04 & 3.74 & 1.04 \\
3 & 3.79 & 1.00 & 3.81 & 1.04 & 3.81 & 1.03 \\
4 & 4.12 & 0.96 & 3.82 & 1.08 & 3.92 & 1.05 \\
5 & 4.05 & 0.94 & 3.76 & 1.01 & 3.85 & 1.00 \\
6 & 3.84 & 0.98 & 3.63 & 1.08 & 3.70 & 1.05 \\
7 & 3.87 & 1.00 & 3.73 & 1.01 & 3.77 & 1.01 \\
8 & 3.81 & 0.96 & 3.83 & 1.03 & 3.82 & 1.01 \\
9 & 3.76 & 1.01 & 3.90 & 1.00 & 3.86 & 1.01 \\
10 & 3.54 & 1.20 & 3.87 & 1.03 & 3.76 & 1.09 \\
\hline & 1Ratings obtained from a Likert-type five points scale ranging from lowest \\
rating to highest rating, i.e. Not At All Satisfied (1), Not Very Satisfied (2), \\
\multicolumn{6}{c}{ Somewhat Satisfied (3), Very Satisfied (4), and Extremely Satisfied (5). } \\
\hline
\end{tabular}

http://ijlter.org/index.php/ijlter 
In addition to the attributes that received the lowest and highest mean ratings about perceived importance, Table 5 indicates the perceived performance of the same ten attributes per educational institution. The three highest-rated attributes about perceived performance at University A are No. 4 (4.12), No. 5 (4.05), and No. 7 (3.87). The results recorded from participants at University B differ in terms of mean value, ranking, and mean value variance. Firstly, it can be noted that the range for the mean value is relatively narrow. The lowest to highest value range is from 3.63 (No. 6) to 3.92 (No. 1). Moreover, the highest-rated attributes about perceived performance are No. 1 (3.92), No. 9 (3.90), and No. 10 (3.87), indicating that students at University B place more emphasis on the perceived performance for a review of the previous class at the beginning of their lecture (No. 1) and being able to learn something valuable (No. 9). Notably, the lowest-rated attributes from the first sample at University A correspond to No. 1 (3.52) and No. 9 (3.54), which were the highest-ranked at University B.

In summary, it can be noted that there is an agreement between both institutions that the virtues and personal traits of the lecturer are perceived as the most important attributes during emergency remote teaching. Attributes that correspond to the lecturers' friendliness, patience, or knowledge are rated higher than, for example, the need for a stimulating or challenging course (Table 6).

Table 6. Comparison of importance-performance ratings $(n=669)$

\begin{tabular}{ccccc}
\hline \multirow{2}{*}{ No. } & \multicolumn{2}{c}{ Importance rating1 } & \multicolumn{2}{c}{ Performance rating } \\
& Mean & SD & Mean & SD \\
\hline 1 & 3.52 & 0.99 & 3.92 & 1.05 \\
2 & 3.62 & 1.04 & 3.80 & 1.04 \\
3 & 3.79 & 1.00 & 3.81 & 1.04 \\
4 & 4.12 & 0.96 & 3.82 & 1.08 \\
5 & 4.05 & 0.94 & 3.76 & 1.01 \\
6 & 3.84 & 0.98 & 3.63 & 1.08 \\
7 & 3.87 & 1.00 & 3.73 & 1.01 \\
8 & 3.81 & 0.96 & 3.83 & 1.03 \\
9 & 3.76 & 1.01 & 3.90 & 1.00 \\
10 & 3.54 & 1.20 & 3.87 & 1.03 \\
\hline
\end{tabular}

Furthermore, while there is a relative agreement about the attributes perceived as most important during emergency remote teaching, there is a discrepancy amongst both institutions about perceived performance during emergency remote teaching. The latter result is probably less surprising, considering that the performance of an online class is largely dependent on the individual lecturer, as well as how the institution manages the ERT. However, it can be noted that participants from both institutions are generally satisfied with the perceived performance during ERT.

The attributes related to perceived performance for both institutions range from the lowest at 3.70 (No. 6) to the highest at 3.92 (No. 4). Also, the result is less surprising as the lowest-ranked attribute is item No. 6, about professionally prepared course material. This is understandable given the short notice to 
convert educational material from traditional classroom teaching into an online environment, as earlier stated by Hodges et al. (2020).

The underlying factors are not clear for the survey items that resulted in very low comparative p-values, as summarized in Table 7 , based on the analysis conducted.

Table 7: Comparison and Independent T-Test's

\begin{tabular}{|c|c|c|c|c|c|}
\hline No. & Mean $^{1}$ & Mean $^{2}$ & Variance & $t$-value & p-value \\
\hline \multicolumn{6}{|c|}{ Importance } \\
\hline 1 & 3.73 & 4.02 & -0.29 & -3.5379 & $<.001$ \\
\hline 2 & 4.03 & 4.17 & -0.14 & -1.6520 & 0.099 \\
\hline 3 & 4.05 & 4.05 & \pm 0.00 & 0.1027 & 0.918 \\
\hline 4 & 4.37 & 4.14 & 0.23 & 2.8501 & 0.005 \\
\hline 5 & 4.27 & 4.18 & 0.09 & 1.0329 & 0.302 \\
\hline 6 & 4.12 & 4.11 & 0.01 & 0.0919 & 0.927 \\
\hline 7 & 4.13 & 4.11 & 0.02 & 0.2802 & 0.779 \\
\hline 8 & 3.98 & 3.91 & 0.07 & $0.8214^{\mathrm{a}}$ & 0.412 \\
\hline 9 & 3.95 & 4.07 & -0.12 & -1.4389 & 0.151 \\
\hline 10 & 3.58 & 4.00 & -0.42 & $-4.5389 a$ & $<.001$ \\
\hline \multicolumn{6}{|c|}{ Performance } \\
\hline 1 & 3.52 & 3.92 & -0.40 & -4.684 & $<.001$ \\
\hline 2 & 3.62 & 3.80 & -0.18 & -2.071 & 0.039 \\
\hline 3 & 3.79 & 3.81 & -0.02 & -0.223 & 0.824 \\
\hline 4 & 4.12 & 3.82 & 0.30 & 3.419 & $<.001$ \\
\hline 5 & 4.05 & 3.76 & 0.29 & $3.608^{\mathrm{a}}$ & $<.001$ \\
\hline 6 & 3.84 & 3.63 & 0.21 & $2.343^{a}$ & 0.019 \\
\hline 7 & 3.87 & 3.73 & 0.14 & 1.696 & 0.090 \\
\hline 8 & 3.81 & 3.83 & -0.02 & -0.194 & 0.846 \\
\hline 9 & 3.76 & 3.90 & -0.14 & -1.739 & 0.082 \\
\hline 10 & 3.54 & 3.87 & -0.33 & $-3.744^{\mathrm{a}}$ & $<.001$ \\
\hline & $\begin{array}{l}\text { le taken } \\
\text { st is sign }\end{array}$ & $\begin{array}{l}n \text { Univ } \\
\text { nt (p< }\end{array}$ & $\begin{array}{l}\mathrm{A} ;{ }^{2} \mathrm{Sampl} \\
\text { suggesting } \\
\text { l variances }\end{array}$ & $\begin{array}{l}\mathrm{n} \text { from } \mathrm{L} \\
\text { ation of }\end{array}$ & $\begin{array}{l}\text { ity B } \\
\text { umption of }\end{array}$ \\
\hline
\end{tabular}

\section{Conclusion and Future Works}

It was the aim of the study to seek validation of previous research results through an increased sample size and to identify whether the perceived satisfaction from undergraduate students varies in a different geographical setting. Everyone involved in the temporary but sudden shift toward virtual learning must recognize that these crises cause disturbances for students, staff, and educators alike. While the coronavirus pandemic will hopefully soon be a distant memory, we should not simply return to our pre-virus teaching and learning practices and ignoring valuable lessons learned from ERT. There are a few noteworthy findings from this study that outline where the educator's emphasis could be placed in a sudden and disruptive move toward virtual teaching. Both data samples suggest an agreement amongst the attributes that students value most and deem as most important in a time when educators struggle to fulfill similar expectations as in the on-site traditional classroom 
arrangement. Furthermore, the study revealed that Thai undergraduate students' perceived performance is generally ranked lower than their perceived expectations, although it should be noted that the perceived satisfaction yielded an overall good result at both institutions. Moreover, emphasis and more attention should be given to younger undergraduate students in their first year of study who struggle more with virtual classrooms than their older peers. Lastly, limitations offer an opportunity for future research; while the authors tried to mitigate possible limitations as far as possible, it is significant to point out that the settings in which the results were collected are geographically limited to the northeastern and southern region of Thailand and not generalizable to a larger population. Furthermore, the demographic profiling of students offers opportunities for future research to quantitatively validate the results and possibly generalize the findings to a larger population.

\section{Acknowledgments}

\subsection{Conflict of interest}

The author would like to declare no potential conflicts of interest concerning the research, authorship, or publication of this article.

\subsection{Data availability}

The data that support the findings of this study are available from the corresponding author upon reasonable request.

\subsection{Funding}

The Faculty of Hospitality and Tourism, Prince of Songkla University funded the project under the Fast Track Data Collection Grant [Contract No. FHT 6400002]. Any opinions or conclusions expressed in this paper are solely the intellectual result of the author(s) and do not reflect the viewpoint of the Faculty or University.

\subsection{Recognition}

The author would like to thank the participants that contributed to the research project by answering the questionnaire.

\section{References}

Busacca, B., \& Padula, G. (2005). Understanding the relationship between attribute performance and overall satisfaction: Theory, measurement and implications. Marketing Intelligence $\mathcal{E}$ Planning, 23(6), 543-561. https://doi.org/10.1108/02634500510624110

Delnoij, L. E., Dirkx, K. J., Janssen, J. P., \& Martens, R. L. (2020). Predicting and resolving non-completion in higher (online) education-a literature review. Educational Research Review, 29, 100313. https://doi.org/10.1016/j.edurev.2020.100313

Downes, S. (2019). Recent work in connectivism. European Journal of Open, Distance and ELearning (EURODL), 22(2), 112-131.

Fay, D. L., \& Zavattaro, S. M. (2016). Branding and isomorphism: The case of higher education. Public Administration Review, 76(5), 805-815. https://doi.org/10.1111/puar.12626

Fuchs K., \& Karrila S. (2021). The Perceived Satisfaction with Emergency Remote Teaching (ERT) amidst COVID-19: An Exploratory Case Study in Higher 
Education. The Education and Science Journal, 23(5), 116-130. https://doi.org/10.17853/1994-5639-2021-5-116-130

Fuchs, K. (2021a). Advances in Tourism Education: A Qualitative Inquiry about Emergency Remote Teaching in Higher Education. Journal of Environmental Management and Tourism, 12(2), 538-543. https://doi.org/10.14505//jemt.v12.2(50).23

Fuchs, K. (2021b). Evaluating The Technology-Enhanced Flipped Classroom Through The Students' Eye: A Case Study. Proceedings of The 3rd International Conference on Research in Education 2021 (vol. 1, pp. 25-33). https://doi.org/10.6084/m9.figshare.14173622

Fuchs, K. (2021c). Preparing Students for Success in a Changing World: The Role of Virtual Whiteboards in the Modern Classroom. Education Quarterly Reviews, 4(1), 151-158. https://doi.org/10.31014/aior.1993.04.01.182

Gelles L. A., Lord S. M., Hoople G. D., Chen D. A., \& Mejia J. A. (2020). Compassionate flexibility and self-discipline: Student adaptation to emergency remote teaching in an integrated engineering energy course during COVID-19. Education Sciences, 10(11), 304. https://doi.org/10.3390/educsci10110304

Hodges, C., Moore, S., Lockee, B., Trust, T., \& Bond, A. (2020). The difference between emergency remote teaching and online learning. Educause Review, 27, 1-12.

Kyne S. H., \& Thompson C. D. (2020). The COVID Cohort: Student transition to university in the face of a global pandemic. Journal of Chemical Education, 97(9), 3381-3385. https:// doi.org/10.1021/acs.jchemed.0c00769

Martin, F., Stamper, B., \& Flowers, C. (2020). Examining Student Perception of Readiness for Online Learning: Importance and Confidence. Online Learning, 24(2), 38-58.

Muhsin, S., Nurkhin, A., Pramusinto, H., Afsari, N., \& Arham, A. F. (2020). The relationship of good university governance and student satisfaction. International Journal of Higher Education, 9(1). 1-10. https:// doi.org/10.5430/ijhe.v9n1p1

Palvia, S., Aeron, P., Gupta, P., Mahapatra, D., Parida, R., Rosner, R., \& Sindhi, S. (2018). Online education: Worldwide status, challenges, trends, and implications. Journal of Global Information Technology Management, 21(4), 233-241. https://doi.org/10.1080/1097198X.2018.1542262

Suikkanen, J. (2011). An improved whole life satisfaction theory of happiness. International Journal of Wellbeing, 1(1), 149-166. https://doi.org/10.5502/ijw.v1i1.6

Sun, A., \& Chen, X. (2016). Online education and its effective practice: A research review. Journal of Information Technology Education, 15(1), 157-190. Retrieved from http://informingscience.org/publications/3502

Themelis, C., \& Sime, J. A. (2020). From Video-Conferencing to Holoportation and Haptics: How Emerging Technologies Can Enhance Presence in Online Education? Emerging Technologies and Pedagogies in the Curriculum, 261-276. https://doi.org/10.1007/978-981-15-0618-5_16

Trower, H., \& Lehmann, W. (2017). Strategic escapes: Negotiating motivations of personal growth and instrumental benefits in the decision to study abroad. British Educational Research Journal, 43(2), 275-289. https://doi.org/10.1002/berj.3258

Weerasinghe, I. S., \& Fernando, R. L. (2017). Students' Satisfaction in Higher Education. American Journal of Educational Research, 5(5), 533-539. http://pubs.sciepub.com/education/5/5/9

Whalen, J. (2020). Should teachers be trained in emergency remote teaching? Lessons learned from the COVID-19 pandemic. Journal of Technology and Teacher Education, 28(2), 189-199. https:// www.learntechlib.org/primary/p/215995 
Wilcox, B., \& Vignal, M. (2020). Recommendations for emergency remote teaching based on the student experience. The Physics Teacher, 58(1), 374. https://doi.org/10.1119/10.0001828

Yamada, A., \& Yamada, R. (2018). The new movement of active learning in Japanese higher education: the analysis of active learning case in Japanese graduate programs. In Active Learning-Beyond the Future, 1(4), 1-16. https://doi.org/10.5772/intechopen.80836

Zlatkin-Troitschanskaia, O., Pant, H. A., \& Coates, H. (2016). Assessing student learning outcomes in higher education: Challenges and international perspectives. Assessment $\mathcal{E}$ Evaluation in Higher Education, 41(5), 655-661. https://doi.org/10.1080/02602938.2016.1169501 